\title{
Aplikasi Linier Ukuran Tubuh untuk Seleksi Fenotipik Bibit Induk Sapi PO di Kabupaten Bojonegoro
}

\author{
Application of Linier Body Measurements for Fenotipic Selection of Dam PO Cattle in Bojonegoro \\ District
}

\author{
A. Gunawan* dan B. W. Putera \\ Departemen Ilmu Produksi dan Teknologi Peternakan, Fakultas Peternakan, Institut Pertaninan Bogor \\ Corresponding E-mail: aagun4780@gmail.com
}

\begin{abstract}
The objective of this research was to predict body weight of Peranakan Ongole (PO) cattle using simple linear body measurement. The height wither (HW), body length (BL), heart girth (HG) and chest widht $(\mathrm{CW})$ were measured in centimeters, using caliper, whereas weaning (WW) and yearling weight (YW) was determined in kilograms using a weighing scale. Results of the correlation coefficient showed that hearth girth (HG) highly correlated with body weight was 0.99 . In all, the body lenght (HW) had the least correlation coefficient was 0.30 on body weight. Results of the stepwise regression showed that HG was a good estimator of body weight $P O$ cattle. The comparison of residuals indicated that only two equations accurately predicted body weight. From these results, it was concluded that body weight of Female PO cattle can be estimated using simple linear body measurement of heart girth especially in most remote areas where farmers are challenged with the unavailability of weighing scale
\end{abstract}

Keywords: dam, linier body measurements, PO cattle, selection

\section{PENDAHULUAN}

Kabupaten Bojonegoro dalam peta pembangunan wilayah di Provinsi Jawa Timur ditetapkan sebagai sentra pengembangan agribisnis ternak khususnya sapi potong. Populasi sapi potong di Bojonegoro tahun 2015 sebanyak 186,861 ekor dengan rincian populasi jantan dan betina masing-masing 74,744 (40\%) dan 112,117 (60\%) ekor Jumlah tahun 2015 ini meningkat sebesar 9\% dari populasi sebelumnya yaitu tahun 2014 sebesar 169,639 ekor (Dinas Peternakan dan Perikanan Bojonegoro 2015). Ketersediaan dan kesesuaian lahan untuk pengembangan ternak sapi potong PO (Peranakan Ongole), di wilayah tersebut cukup tinggi dan sangat memadai. Sapi PO memiliki keunggulan dibandingkan dengan sapi lokal lain diantaranya merupakan tipe sapi dwiguna, tahan serangan penyakit parasit, temperatur udara panas, kelembaban udara rendah, daerah kering, pakan terbatas kualitas dan kuantitasnya, serta efisiensi dalam reproduksi dengan kondisi pemeliharaan peternak rakyat (Aryogi et al., 2007). Namun disamping kelebihan yang dimiliki sapi PO, beberapa kelemahan sapi PO diantaranya laju pertumbuhan/pertambahan berat badan sapi PO dan kulaitas karkas (daging) yang lebih kecil dibanding sapi silangan menjadikan sapi PO dianggap kurang menguntungkan untuk dipelihara dibanding sapi silangan. Perbaikkan mutu genetik ternak melalui sifat pertumbuhan sapi PO dalam upaya mendukung ketersediaan produksi daging sapi sangat penting dilakukan dalam upaya mendukung swasembada daging. Sifat pertumbuhan dipengaruhi beberpa faktor diantaranya faktor genetik, manajemen pemeliharaan, lingkungan sekitar dan ketersediaan pakan. Kaitan dengan faktor genetik, seleksi terhadap bibit sapi PO yang baik merupakan salah satu strategi dalam upaya mengembangkan sapi PO yang unggul dan berkualitas. Penggunaan informasi yang tepat dan sederhana dalam penentuan kriteria seleksi sangat diperlukan dalam mempermudah peternak di lapangan. Seleksi sederhana berdasarkan linier ukuran tubuh masih relevan untuk diaplikasikan dalam upaya pemilihan bibit induk betina sapi PO yang akan dikembangkan lebih lanjut. Selain itu linier ukuran tubuh mempunyai nilai heritabilitas sedang sampai tinggi dan memiliki korelasi yang tinggi dengan sifat pertumbuhan (Afolayan et al., 2007). Wilson (1996) melaporkan heritabilitas sifat pertumbuhan seperti bobot hidup ternak dewasa dan tinggi pinggu masing-masing berkisar antara 0,47-0,51 dan 0,62-0,88. Sifat pertumbuhan seperti bobot sapih dan bobot satu tahun juga dilaporkan memiliki nilai tinggi berkisar antara 0,3-0,4 (Gunawan dan Jakaria 2011; Praharani 2009) yang mengindikasikan program seleksi yang dilakukan terhadap sifat pertumbuhan akan efektif dilakukan daam memperbaikki mutu genetik ternak.

Penelitian ini dilakukan dengan tujuan untuk mengetahui hubungan antara linier ukuran tubuh dan bobot badan betina sapi PO yang digunakan sebagai kriteria seleksi fenotipik bibit Induk sapi PO. Hasil penelitian ini diharapkan dapat digunakan dan membantu peternak di Bojonegoro pada khususnya dan peternak sapi potong pada umumnya secara praktis dalam melakukan seleksi secara fenotipik sapi PO betina calon Induk. 


\section{MATERI DAN METODE}

\section{Lokasi dan Waktu}

Penelitian ini dilaksanakan di kecamatan Kasiman, Bojonegoro pada bulan Juni-September 2014. Pemilihan kecamatan Kasiman pada penelitian ini dikarenakan merupakan kecamatan terbanyak populasi sapi PO yang ada di Kabupaten Bojonegoro.

\section{Materi}

Total sapi PO yang ada di Kasiman didata berdasarkan karkteristik eksternal dengan kategori sapi PO murni atau persilangan. Data tahap pertama yang dikumpulkan pada penelitian ini adalah sapi PO murni berdasarkan ciri eksternal yaitu berwarna putih dan berkalase. Total dari populasi data sekitar 600 ekor sapi yang ada, didapatkan 74 ekor yang diklasifikasikan sebagai Sapi PO murni. Dasar pengelompokan sapi PO murni didasarkan atas karakteristik genetik eksternal diantaranya warna bulu, ada tidaknya tanduk, kalasa dan kriteria lainya menurut SNI. Total 74 ekor sapi PO digunakan pada penelitian ini. Sapi PO tersebut kemudian dilakukan identifikasi melalui pemberian eartag dileher agar dapat mempermudah peternak dalam mengidentifikasi dan melakukan pencatatan. Sapi PO yang sudah teridentifikasi kemudian dilakukan pengukuran sifat kuantitatif diantaranya bobot badan dan liner ukuran tubuh. Pengukuran data bobot badan dan linier ukuran tubuh dilakukan untuk mendapatkan gambaran fenotipik dan kriteria seleksi yang tepat untk sapi PO berdasarkan linier ukuran tubuh. Parameter ukuran tubuh yang dikur diantaranya tinggi pundak, panjang badan, lebar dada dan lingkar dada.

\section{Analisis Data}

Data dianalisis dengan menggunakan analisis deskriptif untuk mengetahui gambaran secara umum karakteristik fenotipk Sapi PO. Hasil analisis dekriptif tersebut dihitung rataanya, kemudian diklasifikasikan sapi PO yang diatas rataan dan dibawah rataan. Kemudian bobot sapi PO diatas rataan direkomendasikan untuk dikembangkan sebagai bibit sapi PO.

Selain analisis deskriptif, analisis regresi dan korelasi dilakukan untuk mendapatkan model pendugaan bobot badan berdasarkan linier ukuran tubuh. Analisis regresi dan korelasi menggunakan perangkat lunak Minitab 16. Model linier regresi yang digunakan sesuai menurut Maschebe and Ezekwe (2010) was:

$$
\mathrm{Y}=\mathrm{a}+\mathrm{bíX}^{\prime}+\mathrm{E} \text {, }
$$

Keterangan:

$\mathrm{Y}=$ Bobot badan

$\mathrm{a}=$ Konstanta

bi $=$ Koefisien regresi

$\mathrm{X} i ́=$ independent variabel

Seperti: X1 = Tinggi pundak (TP) X2 = Panjang badan (BL) X3= Lebar dada (HG) (X4)=Lingkar dada

$\mathrm{E}=$ Standard error
Derajat determinasi $\mathrm{R}^{2}$ merupakan ukuran variabel $\mathrm{Y}$ yang dapat dijelaskan oleh variabel $\mathrm{X}$. Keakuratan persamaan regresi kemudian dibandingakan hasil pengukuran riil berdasarkan timbangan (Sulabo et al., 2006).

\section{HASIL DAN PEMBAHASAN}

\section{Bobot badan Linier Ukuran Tubuh}

Rataan dan standar deviasi bobot badan dan ukuran tubuh sapi PO di kecamatan Kasiman disajikan pada Tabel 1. Rataan bobot badan sapi PO pada penelitian ini $289 \mathrm{~kg}$. Rataan bobot badan sapi PO pada penelitian ini lebih besar dari sapi tropik persilangan yang dilaporkan Dominguez et al. (2003) yaitu sapi Tropicarne (63\% Senepol, 23\% Barzona, 9\% Brahman, and 5\% Charolais) di Meksiko adalah $220.2 \mathrm{~kg}$. Riley et al. (2007) melaporkan pada sapi persilangan Angus, Romosinuano, and Brahman di Amerika sebesar $219.9 \mathrm{~kg}$. Tingginya bobot badan mencerminkan memudahkan dalam mencari bibit pengganti lebih awal, mengurangi biaya ternak pengganti dan kemungkinan tercapainya masa hidup yang panjang (Vergara et al., 2009). Perbedaan antara studi ini dengan studi sebelumnya juga dikarenakan faktor perbedaan breed atau rumpun, dan juga

Tabel 1. Data Deskriptif bobot badan dan linier ukuran tubuh sapi PO betina

\begin{tabular}{lcccc}
\hline Peubah & $\mathrm{n}$ & Mean $(\mathrm{kg})$ & $\mathrm{SE}(\mathrm{kg})$ & $\mathrm{KK}(\%)$ \\
\hline Bobotbadan & 74 & 289,23 & 1,37 & 11,26 \\
Lingkar dada & 74 & 156,97 & 1,2 & 6,59 \\
Tinggipundak & 74 & 127,77 & 1,09 & 7,34 \\
Lebar dada & 74 & 35,18 & 0,42 & 10,08 \\
Panjangbadan & 74 & 112,73 & 1,73 & 10,44 \\
\hline
\end{tabular}

pengaruh dari lingkungan (Jurado et al., 1994).

Hubungan antara Bobot Badan dengan Linier Ukuran Tubuh

Hasil dari analisis sederhana koefisien korelasi dari linier ukuran tubuh terhadap bobot badan sapi PO disajikan pada Tabel 2. Ukuran linier tubuh, lingkar dada (LD), tinggi pundak (TP), panjang badan (PB) dan lebar dada berkorelasi dengan bobot badan sapi PO.

Hasil analisis menunjukkan bahwa lingkar dada menunjukkan korelasi tertinggi dengan bobot badan dengan nilai korelasi sebesar 0,91 . Pada beberapa hasil penelitian menunjukkan lingkar dada memiliki korelasi tertinggi dengan bobot badan seperti yang ditunjukkan pada sapi Bali yaitu sebesar 0,84 dan 0,87 untuk masing masing bobot sapih dan bobot setahun (Gunawan dan Jakaria, 2010). Korelasi yang tinggi antara lingkar dada dan bobot badan juga ditunjukkan pada sapi potong luar negeri (Heinrichs et al., 1992, 2007; Goe et al., 2001). Korelasi adalah salah satu parameter penting yang dapat menggambarkan hubungan antara dua variabel. Korelasi yang tinggi antara lingkar dada dengan bobot badan sapi PO dapat direkomendasikan bahwa seleksi terhadap lingkar dada akan memberikan hasil yang positif terhadap bobot badan dan secara praktikis di lapangan mudah untuk dilakukan. Tingginya korelasi 
Table 2. Koefisien korelasi menunjukkan hubungan antara berbagai ukuran tubuh dengan bobot badan sapi PO.

\begin{tabular}{lllll}
\hline Ukuran Tubuh & $\begin{array}{c}\text { Panjang } \\
\text { badan }\end{array}$ & $\begin{array}{c}\text { Lingkar } \\
\text { dada }\end{array}$ & $\begin{array}{c}\text { Tinggi } \\
\text { pundak }\end{array}$ & $\begin{array}{c}\text { Lebar } \\
\text { dada }\end{array}$ \\
\hline Lingkar dada & 0,31 & & & \\
Tinggi pundak & 0,06 & 0,68 & & \\
Lebar dada & 0,19 & 0,53 & 0,41 & \\
\hline Bobotbadan & 0,3 & 0,91 & 0,69 & 0,54 \\
\hline
\end{tabular}

antara sifat pertumbuhan seperti bobot badan dengan ukuran tubuh menunjukkan bahwa secara umum bobot badan dipengaruhi oleh beberapa gen yang sama dan seleksi terhadap satu sifat akan meningkatkan sifat yang lainnya (Maiwashe et al., 2002). Kekakuratan perhitungan berat dari bobot hidup melalui ukuran tubuh seperti lingkar dada memberikan kemudahan bagi peternak di pedesaan yang sering terkendala dengan fasilitas alat timbangan untuk melakukan penimbangan bobot badan (Cam et al., 2009). Hasil penelitian ini dapat digunakan oleh peternak sapi PO di kecamatan Kasiman pada khususnya dan kabupaten Bojonegoro pada umumnya dalam menduga berat hidup sapi PO berdasarkan lingkar dada yang secara pengukuran cukup praktis dan mudah untuk dilakukan.

\section{Penduga Bobot Badan melalui Lingkar Dada}

Ketepatan pendugaan antara ukuran tubuh dan bobot badan riil atau sebenarnya dapat diduga dengan menggunakan metode regresi sederhana. Metode regresi ini digunakan utuk menentukan variabel ukuran tubuh penting yang dapat dijadikan sebagai indikator yang baik dalam menentukan berat dari bobot badan hidup. Metode regresi sederhana dapat digunakan sebagai pendugaan terbaik dalam menentukan bobot badan sapi PO. Persamaan regresi anatara bobot badan dengan ukuran tubuh sapi PO disajikan pada Tabel 3.

Lingkar dada merupakan parameter terbaik dalam menduga bobot badan sapi PO dengan tingkat keragaman yang dapat dijelaskan sebesar 99,8 (Tabel 3). Penelitian ini sesuai dengan hasil penelitian pada sapi Bali bahwa lingkar dada merupakan variabel penduga bobot badan pada bobot sapih dan setahun dengan total keragaman masing-masing sebesar 71 dan 75,9\% (Gunawan dan Jakaria 2010). Hal yang sama didapatkan pada penelitian sapi tropis luar negeri yaitu Sapi di Nigeria (Nwosu et al., 1985) dan sapi perah (Heinrichs 1992) yang mengembangkan persamaan lingkar dada untuk menduga bobot badan. Sdangkan linier ukuran tubuh lainnya yaitu tinggi pundak (TP), lebar dada (LD) dan panjang badan (PB) dapat menjelaskan masing-masing hanya sebesar 47,2; 28,3 dan 7,8 dari total keragaman yang mengindikasikan ukuran tersebut bukan

Table 3. Hasil analisis regresi bobot badan sapi PO dengan ukuran tubuh

\begin{tabular}{lll}
\hline Komponen & Prediction equation & R2 \\
\hline Lingkar dada & $\mathrm{BB}=-205+3,15 \mathrm{LD}$ & 99,8 \\
Tinggipundak & $\mathrm{BB}=-18,2+2,41 \mathrm{~PB}$ & 47,2 \\
Lebar dada & $\mathrm{BB}=114+4,97 \mathrm{LD}$ & 28,3 \\
Panjang Badan & $\mathrm{BB}=195+0,834 \mathrm{~PB}$ & 7,8 \\
\hline
\end{tabular}

merupakan parameter penduga yang baik dalam menduga bobot badan sapi PO.Hasil ini sesuai dengan penelitian yang dilaporkan pada ternak sapi lainnya (Groesbeck et al, 2003; Sulabo et al, 2006 and Machebe dan Ezekwe, 2010). Tingginya korelasi antara lingkar dada dengan bobot badan mengindikasikan lingkar dada merupakan variabel yang baik dalam menduga bobot badan pada sapi PO terutama di daerah pedesaan dimana adanya keterbatasan fasilitas seperti alat penimbangan dan dan kondisi geografis. Korelasi yang tinggi dan positif mengindikasikan kesesuaian dengan pendugaan bobot badan (Rahman, 2007). Hasil penelitian ini menunjukkan bahwa dengan pengukuran yang cermat melalui lingkar dada, bobot badan sapi PO dapat diduga secara akurat. Sebagai contoh, lingkar dada sapi PO sebesar $150 \mathrm{~cm}$, ketika dimasukan ke dalam model regresi $\mathrm{BB}=$ $205+3,15$ (150) (Tabel 3), prediksi BB sapi PO sekitar $267,5 \mathrm{~kg}$. Hal ini cukup mendekati BB riil dari sapi PO tersebut yaitu sebesar $266,26 \mathrm{~kg}$. Hasil ini sesuai pendapat Cam et al (2009) yang melaporkan persamaan regresi cukup dekat menggambarkan bobot badan sebenarnya

Hasil pendataan dan pengukuran di lapangan menunjukkan bahwa seleksi secara sederhana berdasarkan fenotipik dapat dilakukan sebagai kriteria seleksi untuk memilih individu sapi PO oleh peternak. Seleksi sifat berdasarkan fenotipik bobot badan pada sapi PO disajikan

Tabel 4. Seleksi sifat berdasarkan fenotipik bobot badan pada sapi PO

\begin{tabular}{llllll}
\hline Sifat & $\mathrm{n}$ & Rataan & $\mathrm{SE}$ & Min & Max \\
\cline { 2 - 6 } & & $(\mathrm{kg})$ & $(\mathrm{kg})$ & $(\mathrm{kg})$ & $(\mathrm{kg})$ \\
\hline BB Rataan & 74 & 289,23 & 3,79 & 194,48 & 352,84 \\
BB diatas rataan & 42 & 310,93 & 2,72 & 290,31 & 352,84 \\
BB dibawah & 32 & 260,74 & 4,38 & 194,48 & 288,47 \\
rataan & & & & & \\
\hline
\end{tabular}

pada Tabel 4 .

Berdasarkan Tabel 4 diketahui bahwa sapi PO betina yang dapat digunakan sebagai kandidat bibit induk yang memiliki bobot badan diatas dari rataan yaitu mulai dari sapi betina PO dengan memiliki bobot badan minimal $290 \mathrm{~kg}$ (Tabel 4). Hasil pengamatan sapi PO yang dapat disiapkan untuk induk didapatkan sebanyak 40 ekor. Jumlah induk tersebut diharapakan dapat dikembangkan untuk mendapatkan hasil anakan PO dengan kualitas terbaik karena memiliki bobot badan yang diatas standar. Hasil dari seleksi indukan yang didapatkan diharapkan dapat digunakan untuk perbanyakan populasi.

\section{KESIMPULAN}

Lingkar dada merupakan parameter terbaik dalam menduga bobot badan sapi PO yang ditunukkan dengan nilai korelasi tertinggi dengan bobot badan yaitu sebesar 0.91 . Kekakuratan perhitungan berat dari bobot hidup melalui ukuran tubuh seperti lingkar dada memberikan kemudahan bagi peternak di pedesaan yang sering terkendala dengan fasilitas alat timbangan untuk melakukan penimbangan bobot badan. Hasil pengamatan sapi PO yang dapat disiapkan untuk induk direkomendasikan memiliki bobot 
badan minimal $290 \mathrm{~kg}$.

\section{DAFTAR PUSTAKA}

Cam MA, M Olfaz and E Doydan. 2010. Body measurements reflect body weights and carcass yields in Karayaka sheep. Asian Journal of Animal and Veterinary Advances 5(2), 120-127

Dinas Peternakan dan Perikanan Bojonegoro. 2015. Populasi sapi di Bojonegoro terus meningkat. Pemerintah Kabupaten Bojonegoro. http://www. bojonegorokab.go.id/berita/baca/1202/Populasi-Sapidi-Bojonegoro-terus-Meningkat\#

Goe MR, JR Alldredge and D Light. 2001. Use of heart girth to predict body weight of working oxen in Ethopian highlands. Levestock Prod Sci, 69:187-195

Groesbeck CN. 2003. Use heart girth to estimate the weight of finishing pigs. Kansas State University Cooperative Extension Service Swine Update Newsletter - Spring

Gunawan A. \&Jakaria. 2011. Genetic and non genetics effect on birth, weaning and yearling weight of Bali cattle. Med. Pet.34: 93-98. doi: 10.5398/ medpet.2011.34.2.93

Heinrichs AJ, HN Erb, GW Rogers, JB Cooper and CM Jones. 2007. Variability in Holstein heifer heart-girth measurements and comparison of prediction equations for live weight Preventive. Vet. Med.78, 333-338

Jurado JJ, A. Alonso, \& R. Alenda. 1994. Selection response for growth in Spanish Merino flock. J. Anim. Sci. 72:1433-1440

Machebe NS. and AG Ezekwe. 2010. Predicting Body Weight of Growing-Finishing Gilts Raised in the Tropics using Linear Body Measurements.Asian J.Exp. BiolSci 1(1):162-165

Maiwasha AN, MJ Bradfield, HE Theron, JB Van Wyk. 2002. Genetic parameter estimates for body measurements and growth traits in South African Bonsmara cattle. Livest. Prod. Sci. 75, 293-300.

Nwosu CC, FN Akhionbare, and IE Iboh (1985). Characterization of cattle in Nigeria body measurements. Beitrage trop. Landwirtsch.Veterinärmed.,(23): 89-97.

Riley DG, CC. Chase, SW. Coleman, \& TA. Olson. 2007. Evaluation of birth and weaning traits of Romosinuano calves as purebreds and crosses with Brahman and Angus. J. Anim. Sci. 85, 289-298.

Vergara OD, MA. Elzo, MF. Ceron- Munoz, \& EM. Arboleda. 2009. Weaning weight and post weaning gain genetic parameters and genetic trends in Blanco Orejinegro-Romosinuano-Angus-Zebu multibreed cattle population in Columbia. Livest. Sci. 124: 156-162. 